\title{
Article
}

\section{Death of a Watchdog: Reduced Coverage of Coroners' Inquests by Local Media}

\author{
Binns, Amy and Arnold, Sophie
}

Available at http://clok.uclan.ac.uk/29519/

Binns, Amy ORCID: 0000-0002-9173-3108 and Arnold, Sophie (2021) Death of a Watchdog: Reduced Coverage of Coroners' Inquests by Local Media.

Journalism Practice, 14 (10). pp. 1460-1478. ISSN 1751-2786

It is advisable to refer to the publisher's version if you intend to cite from the work. http://dx.doi.org/10.1080/17512786.2020.1776143

For more information about UCLan's research in this area go to

http://www.uclan.ac.uk/researchgroups/ and search for < name of research Group>.

For information about Research generally at UCLan please go to

http://www.uclan.ac.uk/research/

All outputs in CLoK are protected by Intellectual Property Rights law, including Copyright law. Copyright, IPR and Moral Rights for the works on this site are retained by the individual authors and/or other copyright owners. Terms and conditions for use of this material are defined in the policies page.

\section{CLoK}

Central Lancashire online Knowledge www.clok.uclan.ac.uk

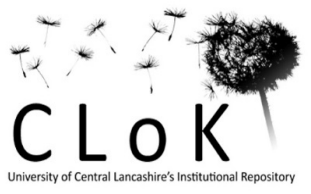




\section{Death of a Watchdog: \\ Reduced Coverage of Coroners' Inquests \\ by Local Media}

Dr Amy Binns, University of Central Lancashire

Sophie Arnold, University of Central Lancashire

Corresponding author: abinns@uclan.ac.uk 


\section{Abstract:}

This research project has four strands: quantifying reporting of inquests; quantifying publicly available information from coroners' offices; investigating reasons for lack of coverage; and establishing solutions for making accounts and verdicts of inquests more accessible in a changed media landscape.

Results show an overall reporting rate of only 11 per cent. Coverage varies wildly, with some "news deserts" where inquests are rarely reported. Deaths of younger people are more likely to be reported, as are male deaths.

Information provided by coroners' offices also varies wildly despite national guidelines updated three years' ago recommending greater transparency.

This report investigates the reasons for a lack of public scrutiny of coroners' courts by local media. Deaths may go unreported due to: the collapse of local newspapers and reduced staff in surviving organisations; the centralisation of police and newspaper offices, leading to fewer direct contacts between police and journalists; and a general cultural shift of passing media inquiries to a "communications team" which means news is filtered to give a more positive sense of police success.

Recommendations: better implementation of existing guidelines: routine release of information regarding all deaths at which emergency services attend; and closer relationships with coroners' officers at inquest opening stage.

Keywords: journalism; coroner; inquest; public interest journalism; civic journalism; public inquiry; local media; local newspapers

\section{Introduction}

This project stems from our concern about the reduced public scrutiny of coroners' courts due to the collapse of local newspapers. Deaths may go unreported at the time due to centralisation of both police and newspaper offices, which has led to fewer direct contacts between police and journalists. A general cultural shift of passing media inquiries to a "communications team" of PR specialists also means news is likely to be filtered to give a more positive sense of police success.

Due to falling newspaper ad revenue, there is a shrinking number of local journalists. Fewer attend court, thus many more inquests go unreported. Some deaths are missed altogether.

The importance of this cannot be underestimated. Ian Murray, executive director of the Society of Editors, said: "There is no more important public inquiry than that of an investigation into the death of a citizen. Once those go behind closed doors - through lack of interest, lack of resources, or a wish to become more efficient - then we are on a slippery slope." 
This research project has four main strands: quantifying reporting of inquests; quantifying publicly available information from coroners' offices; investigating reasons for lack of coverage; and establishing solutions for making accounts and verdicts of inquests more accessible in a changed media landscape.

Research question 1: What percentage of inquests are covered?

Research question 2: Are certain types of inquests more likely to be covered?

Research question 3: What information is available to the public from coroners' offices before and after inquests?

Research question 4: What factors contribute to editors' decisions to cover or not cover inquests?

\section{Literature Review}

In Britain, a study by trade journal Press Gazette in 2018 showed that a total of 40 papers closed in 2017, bringing the total number of closures since 2005 to 228. Ten new titles were opened in 2017, leaving a net loss of 30 . In total, 45 net jobs were lost with 252 jobs lost, but about 207 jobs created, including the creation of 150 BBC local democracy roles (Kakar, 2018).

A report by King's College, London, (Moore, 2016) found reduced plurality due to the dominance of four local media groups. The authors found that even where local newspapers had survived, they had been hollowed out with reduced editorial staff. Offices were often centralized, with the closure of town centre offices removing journalists many miles from the communities they served.

This is a worldwide trend. Local Journalism: The Decline of Newspapers and the Rise of Digital Media, published by Reuters Institute, drew together evidence from across Europe and the US (Nielsen, 2015), concluding that most local news reporting had declined.

A report by the US Public Broadcasting Service explored the lack of local news was causing 'news deserts' with closures and job losses not just restricted to newspapers but also digital news upstarts such as BuzzFeed (Woodruff, 2019). A similar report by CBS (the Columbia Broadcasting System and commercial equivalent) notes that the loss of local newspapers in the US is 'leaving communities in the dark'. Closure have affected 1,400 towns cities, often rural, low income areas with ageing populations (CBS, 2019).

What effect does this have? There is good evidence that a thriving local press has positive results for communities. Bruns and Himmler's study of 150 Norwegian newspapers found that areas with increased local newspaper circulation were associated with higher levels of local government efficiency thanks to better accountability of local politicians (Himmler, 2011). A Japanese study produced similar results (Yazaki, 2017). A US study found that in areas not covered by local press, congressmen worked less for their communities by several measures and were less likely to vote against the party line. These areas also had reduced federal spending (Stromberg, 2010). 
Local democracy was also affected: Rubado and Jennings (2019) found that areas served by newspapers with relatively sharp declines in newsroom staffing had, on average, significantly reduced competition in mayoral races and were associated with lower voter turnout.

Coverage of inquests can result in specific and effective campaigns. An inquest into the death of 22year-old Jill Griffiths, of Skipton, after being given an overdose of the painkiller diamorphine by a GP, led to a Yorkshire Post campaign for better drug labelling (Binns, 2001). The "Make it Clear, Make it Safe" campaign resulted in an Early Day Motion led by Yorkshire MP David Curry on the issue, which congratulated the newspaper on its work (House of Commons, 2001). In early 2003, the Government unveiled plans to radically improve medicine labelling (Yorkshire Post, 2003).

Many commentators have expressed concerns that the loss of local reporting reduces the amount of both "everyday watchdoggery" (Gans, 2010) and major public interest investigations (Firmstone, 2016). Bagshaw (Bagshaw, 2019) reported that one major area of cutback was on reporting of magistrates and crown courts.

According to The Guardian in 2019, the creation of local democracy reporters have gone some way to fill the gaps left by closed newspapers but notes that it has not yet extended to courts, high street news or campaigning on local issues such as housing (Waterson, 2019). It notes that in places like Walsall in the Midlands where all local newspapers have closed, residents increasingly rely on 'unreliable word-ofmouth' to find out what is going on.

It seems reasonable to extend these concerns about public accountability and scrutiny to inquests. However, research about press reporting of inquests is a neglected area.

There is some research about the effects of reporting in suicide cases leading to further suicides. (Ziesenis, 1991) (Barraclough, 1977) and about the distressing or therapeutic effects of the inquest process on the relatives of suicides: (Spillane et al, 2019) (Tait \& Carpenter, 2013).

Conversely, Fagan, Lyons and Smyth examined the content of reports of inquests related to alcohol, and noted that the press could play a role in preventing deaths related to alcohol through their reporting of inquests (2014).

There has also been some examination of the importance of open justice, especially where death has occurred at the hands of the state, or in custody (McIntosh, 2016).

This is a principle which is generally acknowledged by the Chief Coroner who issued guidance on what information should be made available before an inquest is held. The guidance states that the date, time and place of the inquest must be made available, preferably on a website and at least seven days in advance. It also states that the name of the coroner (where known), whether it is a jury inquest, the name and age of the deceased and the date and place of death (home or hospital) should be provided. It adds that it is not appropriate to provide a medical cause of death, brief circumstances of death or likely conclusion. It goes on to say that the right of the public and therefore, the press, to attend means little unless notice of the hearing is given (Thornton, Guidance No.25 Coroners and the Media, 2016).

In the UK, many deaths are reported to coroners but not all result in an inquest. Following the Harold Shipman case in 2000 (Sommerlad, 2018), an inquiry was set up to review death certification and the investigation of deaths by coroners. It published its findings in 2003 and concluded that all but 'expected 
deaths' should be reported to the coroner (gov.uk, 2003). However, since 2009, coroners can sign off a death before a full inquest is held but after preliminary inquiries if the cause was natural (Thornton, 2016). Full inquests were held for $15 \%$ of the total number of deaths referred to the coroner in 2015 (Thornton, Guidance No.25 Coroners and the Media, 2016). Around 7\% of all deaths result in a full inquest hearing. This is higher than any comparable jurisdiction internationally (Lucraft, 2018). The introduction of Medical Examiners (MEs) to advise doctors has been explored but has not yet been implemented (Lucraft, 2018).

\section{Methodology}

This project uses a mixed methods approach combining quantitative and qualitative analysis. REF HERE Quantitative data was generated in two ways. First, through a comparison between public listings of inquests and google news alerts in sample areas; and secondly, through a national survey of coroners' publicly available listings.

Nine sample areas were chosen to give a variety of urban and rural areas across the country. Scotland was not included as they use a different inquest system. The sample areas were: Birmingham, Blackpool, Bradford, Dorset, Exeter, Newcastle, Preston, South Wales, Surrey. London was not included because of the complications of a large number of local media and courts, with confusing crossover between them. These areas are covered by a range of regional press companies including Reach, JPI Media, Newsquest.

For five consecutive weeks in May and June 2019, the coroners' or local councils' websites were checked for upcoming cases. We only considered full hearings and excluded openings, pre-inquest reviews and treasure inquests. The authors then listed these with all the available data on spreadsheets. Coroners are obliged to provide listings of hearings, but they are free to choose how to do this. Some offered searchable records far in advance and kept historic listings online. Others provided a weekly pdf which was changed on Fridays or Mondays, so finding past cases was not possible. All sites were checked at least twice a week to capture new or cancelled hearings.

Coroners are also free to choose how much detail they provide about upcoming cases. Some offered the subject's age, town of residence, date and place of death and other details. Some only listed names and the time of the hearing. This meant we had limited data to answer research question 2. However, this reflects the reality of how much data journalists have when making decisions about where to allocate resources.

A dedicated google account was set up for this project, with gmail. Google news alerts were set up on the words "coroner OR inquest" for all the media companies online in those areas. These included local newspapers and radio stations with an online presence. For example, for Bradford, an area that covers 1.3million people, we set up news alerts for nine local newspapers. The news alert was defined as: inquest OR coroner site:http://www.wharfedaleobserver.co.uk/ OR site:yorkshirepost.co.uk OR site:http://www.thetelegraphandargus.co.uk/ OR site:https://www.examiner.co.uk/ OR site:http://www.keighleynews.co.uk/ OR site:http://www.cravenherald.co.uk/ OR site:todmordennews.co.uk OR site:hebdenbridge.co.uk OR site:halifaxcourier.co.uk OR site:hebdenbridgetimes.co.uk OR site:brighouseecho.co.uk OR site:johnstonpress.co.uk 
These news alerts generated emails with links to any stories published on any of the sites in that group featuring the words coroner or inquest. These links were cross-referenced against the spreadsheets of cases for those areas. Often a link was not relevant: it might refer to a historic case; or a significant national case covered as part of the Press Association service of national round-ups for the local press; or a future case; or might use the word inquest informally. However, enough alerts to cases listed in our spreadsheets were generated for us to know the system was working correctly.

At the close of the project, the spreadsheets were analysed to answer research questions 1 and 2 .

Research question 3 was answered by checking the data available on publicly available listings for all the 88 coroners' offices listed on the Society of Coroners website. Some of these had their own sites or sent email lists but most used council sites. Occasionally, listings were combined for areas, for example, Yorkshire North East and Yorkshire North West. This brought the total number of offices analysed down to 84 .

To answer research questions 2 and 4, we interviewed six reporters and editors from several local newspapers representing various media groups. These semi-structured interviews allowed us to investigate the background to the lack of coverage and also reporters' views on what would make independent scrutiny more viable. Journalists were encouraged to comment both on the wider issue, and on specific local pressures or cases that concerned them.

Subjects covered in interviews included: staffing levels; ability to find information from police and coroners; how editorial decisions were made about which inquests to cover; satisfaction or dissatisfaction with their own coverage; how coverage had changed over time (depending on the length of time they had been working).

The interviewees were: Amy Farnworth, Lancashire Telegraph reporter; Jenny Simpson, Lancashire Post news editor, with 12 years' experience; Andy Martin, Bournemouth echo, editor, 30 years' experience; Alistair Shand, Keighley News, chief reporter, 34 years' experience; Wayne Ankers, editor, Huddersfield Examiner, more than 20 years experience; Gavin Thompson, Western Daily Press, editor.

\section{Results}

\section{Research question 1: What percentage of inquests are covered?}

In total, we listed 358 inquests (not including openings) across our nine coroners' courts. Of these, 40 (11\%) were covered by local press. Coverage varied widely, as table 1 shows.

\begin{tabular}{|l|l|l|l|}
\hline Court & Inquests & Covered & Notes \\
\hline Birmingham & 56 & 1 & Prisoner suicide covered by INQUEST \\
\hline Blackpool & 20 & 1 & \\
\hline Bradford & 64 & 1 & A fall from Ben Nevis covered by Press Association \\
\hline
\end{tabular}




\begin{tabular}{|l|l|l|l|}
\hline Dorset & 55 & 4 & \\
\hline Exeter & 29 & 9 & \\
\hline Newcastle & 13 & 0 & \\
\hline Preston & 55 & 14 & $\begin{array}{l}\text { All in Blackburn-based Lancashire Telegraph, only one in } \\
\text { Preston-based Lancashire Evening Post }\end{array}$ \\
\hline South Wales & 41 & 6 & $\begin{array}{l}\text { Two of these covered by nationals: murdered mother and } \\
\text { daughter Christine and Lucy Lee, and a suicide at Deepcut } \\
\text { barracks of Geoff Gray. }\end{array}$ \\
\hline Surrey & 25 & 4 &
\end{tabular}

\section{Research question 2: Are certain types of inquests more likely to be covered?}

News sites tended to report on the deaths of younger people more frequently than the deaths of older people. We conducted analysis only for the four areas with a higher number of reported inquests, and where ages were given in coroners' listings. The results are shown in Table 2.

\begin{tabular}{|l|l|l|}
\hline Court & Average age of all subjects & Average of subjects in reports \\
\hline Dorset & 67 & 38 \\
\hline Exeter & 58 & 43 \\
\hline Preston & 55 & 40 \\
\hline Surrey & 61 & 32 \\
\hline
\end{tabular}

This supports what we have found from speaking to reporters and editors (see research question 4 above). The deaths of younger people tend to be of unnatural causes and are therefore seen as more like to be in the public interest or in the interests of the public

In terms of gender, 31 of the inquests that were reported by news sites were male, only nine were female. This may relate to the increased number of young male suicides and accidental deaths compared to female.

In seven of the 40 inquests reported, recommendations or criticism by the coroner were reported. The most common conclusion was suicide, eight out of the 40 , closely followed by narrative verdicts with seven. A full breakdown of inquest conclusions is provided below.

The conclusions were as follows:

Suicide -8

Narrative verdict -7

Drugs-related death -5

Road Traffic Collision - 5 
Accidental death -4

Misadventure -4

Unknown/not reported - 3

Open conclusion -2

Natural causes -1

Unlawful killing - 1

Very occasionally inquests were covered by news organisations outside of the local area, but not by the local outlets. We have not included these in our figures. For example, an inquest into the death of a mother-of-four, Michelle Gerrard, held at Preston Coroners Court, was covered by the Manchester Evening News. The death occurred in Chorley and had not been covered by the Lancashire Evening Post which covers this area. It seems likely that the MEN was contacted by a member of the deceased's family as her mother was quoted at length in the article.

Similarly, an inquest at Blackpool Coroners' Court into the death of a young woman, Kirsty Blanksby, was covered by the Mirror but not by the local news. The story was of interest to the Mirror as the deceased's identical twin sister had died 15 years before. Petra Blanksby's death was widely covered in 2003 as she took her own life in prison, so it is likely a reporter who was around at that time was aware of the story and therefore wanted to cover the latest inquest.

Several of the inquests reported received coverage nationally as well as locally. The inquest of mother and daughter Christine and Lucy Lee lasted several weeks and appeared repeatedly on a number of national and local websites. It was covered by the Press Association, meaning many organisations used this copy. The two women were killed by puppy farmer John Lowe, who was convicted of murder in 2014 but died in prison four years later. The inquest found that police failings had contributed to the murder.

The Patrick Boothroyd inquest in Bradford, Walter John Kingdom's inquest in Exeter and Geoff Gray's in Surrey also received wide national coverage as they were reported by the Press Association. Boothroyd died following a fall on Ben Nevis and Kingdom was a well-known wildlife presenter. Gray shot himself at army barracks at Deepcut, one of four young recruits to die there between 1995 and 2002 amid claims of abuse and bullying. Marcus McGuire took his own life at HMP Birmingham and his inquest was covered by BBC as well as Birmingham Live and was attended by INQUEST. The inquest into the death of Jasmine Bush, who was hit by a train, was reported locally and in a handful of nationals.

\section{Research question 3: What information is available to the public from coroners' offices before and after inquests?}

The Society of Coroners' lists 88 separate coroners' courts. However, some of these appear to have been folded together and the information about their listings appears in a single place online. For example, Yorkshire North East and Yorkshire North West were folded together as North Yorkshire, and the listings are available on the North Yorkshire County Council website. In total therefore, we have 83 listings. 
Almost all offices offer at least some information online, ten through their own website and 65 through a local council website. Five districts provide information through email lists sent to interested parties including media: Cheshire, London Inner West, Cornwall, Wiltshire and Swindon, and Derby and Derbyshire.

Gwent called the local press with dates. North West Wales provided contacts online but did not respond to emails. Gateshead and North Tyneside provided an incorrect phone number and could not be tracked down even by the police switchboard operator.

The timing of the provision of information varied widely. Some uploaded a pdf once a week on Friday or Monday morning, replacing it each week. This makes it much more difficult for journalists to plan or research. Others had searchable databases of historic and future cases.

The amount of information provided also varied widely. Aside from date and time of the hearing, coroners' offices commonly provided a selection of 11 types of information: name, age (or both date of birth and date of death), date of death, if the death occurred in a hospital, town of death, town of residence, more specific address, estimated duration of hearing, hearing type, date of opening and verdict.

Some, including Southampton, South Wales and West Sussex, also said if the death occurred outside such as in a road traffic accident or lake. Sunderland stated if the death occurred in a hospital or care home. Derby and Derbyshire, Cheshire and Yorkshire South East provided an indication of type of death, such as fall, toxicology etc. It is worth noting that both Cheshire and Derby and Derbyshire provide information via an email list, not a publicly accessible website.

Hertfordshire provided nine of these pieces of information, followed by four offices providing eight: Birmingham and Solihull; Cambridgeshire and Peterborough; Cheshire; and Staffordshire South. In total, 39 coroners' offices, almost half the total, provided six or more of these pieces of information. At the other end of the scale, London North and Yorkshire West Western (Bradford) provided only the name of the deceased.

Very few coroners' offices provided conclusions after the inquest. These were: Lancashire; Essex; Worcestershire; Staffordshire; and Hertfordshire.

There are other ways in which journalists may find out about an inquest, rather than through listings provided by the court. A reporter in Blackpool told us that he had been contacted by the family of the deceased in one case and asked to cover the inquest to ensure failings in the deceased's care by a hospital was reported. Some reporters may follow a case from first hearing about a death, possibly from police.

\section{Research question 4: What factors contribute to editors' decisions to cover or not cover inquests?}

Several key themes emerged: the lack of newsroom resources and the need for background knowledge when deciding what to cover because of stretched resources in particular. 
They also spoke of issues with police and coroners, key themes including: the loss of personal relationships due to their own and the police's stretched resources; increased police wariness and changed agendas of communication teams; difficulties getting information and late information.

Despite these problems they reiterated their continued commitment to public interest reporting. They still felt that inquests were important hearings which should receive attention. There was no implication that the lack of coverage was due to a lack of interest.

\section{The lack of newsroom resources}

Unsurprisingly given the well-documented problems of local news organisations, this was given by all interviewees as a key factor in the lack of coverage.

Editor Andy Martin said: "We have gone from 75 to 19 reporters in the last ten years at the Bournemouth Echo."

Western Daily Press Editor Gavin Thompson said: "With small news rooms you are making more difficult decision about resources. Can you send someone out to spend a whole afternoon on one story? You are only going to do it if you are pretty confident you are going to get something news worthy about it."

Geography and merging of newsrooms was also an issue. Chief reporter Alistair Shand described how the Keighley News office had left Keighley, a busy Northern town of 70,000 people, and moved to the Skipton offices of the Craven Herald 12 miles north. However, the inquests were held in Bradford, to the south of Keighley.

Mr Shand said: "We rely on the Bradford Telegraph and Argus in terms of court coverage. Obviously the T\&A is in the same boat as everyone else in terms of staff so it's a bit hit and miss now."

\section{The need for background knowledge}

Journalists generally said they would only attend an inquest if they have background information about the case that convinces them that it is worth significant due to the lack of resources described above. The coroners' lists in themselves rarely contain enough information to enable staff to make a decision. Journalists will usually check names against their own websites to find out if they have covered the case before. If not, they are less likely to go. This means that if serious cases are missed at time of death, they are also likely to be missed at time of inquest.

Several interviewees said they it was not unusual to miss deaths at the time, often due to lack of information from the police. Journalists did not appear to pick up detailed information from inquest openings.

Mr Thompson said sometimes police did not report unusual deaths to the press for several weeks, as in the case of a University of Bath student, Alex Green, who was found unconscious at a bus stop and later died in hospital. A witness appeal was only released three weeks later. 
He said: "They didn't see any need to tell us about it. They are not interested in a perception of a lot of crime in the area so only [tell us] when they are trying to catch someone. They don't see it as their role to provide information."

Mr Ankers, Mr Martin and Mr Shand agreed that press releases and e-fits for witness appeals could be a month late - they were only used as a last resort.

Mr Shand said: "They come to us when they get to a total dead end with an inquiry. Unless you know about something and go to them it's very rare they come to you."

Jenny Simpson, Lancashire Post News editor, said it was a mixed picture in her area, with problems more due to stretched police resources than unwillingness. She said: "We depend on information from the public so they might tell us there is a lot of police activity in an area and we will contact the police to find out what is going on in a situation that they wouldn't have put out a press release.

"I don't think they set out to withhold information, but sometimes they aren't terribly fast at coming back to us. They have never told us we can't have the information, we just have to be persistent sometimes, but it is an issue of resources rather than police policy."

\section{Loss of personal relationships}

The loss of personal relationships between news reporters, police and coroners' offices was referred to by all reporters.

Ms Simpson said there had been a dedicated inquest reporter before she arrived (more than 12 years ago). It wasn't her sole job, but she had gone through the list and attended all significant cases. This was no longer possible: “We wouldn't send someone speculatively and so we don't have someone popping in regularly and having a chat."

Mr Shand, whose office had moved to the North of Keighley to Skipton, was further hamstrung when the police office also closed, moving South to Bradford, a 50 minute drive away. He said: "I used to call round to police stations in the mornings and have a chat with them, they would tell you what had happened overnight. I would speak to Detective Inspectors. Some might be off the record but he would tell you everything. It was great because you got the full story even if you couldn't report it at the time."

Mr Ankers, who had recently become editor, said building up personal relationships with officials was one of his priorities. His team ring the police press office every morning: "We used to call CID and that relationship has sort of dwindled. Sometimes it can be down to the fact that they are unhappy with what we have reported but it can also be due to them being extremely busy.

"You ring CID and you might get an officer you spoke to previously but you can also ring and get someone you have not got a relationship with and get nothing at all.

"You would think the local paper and website would still have working relationships but it depends to be at my level with the chiefs superintendents rather than a reporter level with the Detective Inspectors.

"That's partially our fault because we have got smaller resources. It's not the same person making the calls every day. That's how you build relationships with them." 


\section{Increased police wariness and changed agendas of communication teams}

Lack of resources was not the only issue. Several journalists mentioned a more insidious culture change to a suspicion of the local press leading to automatic refusals.

Mr Martin described this as part of a pattern of a more defensive public sector. He said: "I go back to when you could have direct contact with police detectives. Now it's all done through teams of communication officers - in inverted commas - who put up barriers.

"The new breed come in with a different mind et about 'you should not talk to the press except on your own terms'. Police and local authorities want to set their own news agenda. They have news teams who pump out their own news releases and propaganda. Obviously the coroners don't do that but it's part of a pattern that it's more difficult to get information out of them...

"At weekends it's virtually impossible to get information out of the police. The control room is supposed to help us out but they just say they are not allowed to or they say you have to get a press officer later. It's like getting blood out of a stone.

"It feel very strongly about this wall that's being put up around the public sector."

Mr Thompson agreed: "The police are very wary of the contact they have with the media. There's press office are quite controlling of direct relationship you might have had."

Mr Shand said: "All our dealings have to be through the press office. There are one or two neighbourhood policing officers who use Twitter so sometimes you can direct them and sometimes they will get back to you.

"If we attend an incident the bobbies at the scene won't say anything. It's the same with the council."

Journalists described relationships with coroners' officers as being more mixed, varying from "great" to "reasonably helpful", to more problematic. Mr Martin said relationships had deteriorated after a change of staff some months earlier.

He said: "The coroner's officer used to give us the heads up about stories... [Now] we are missing things.... We are always complaining about the fact that we are not aware that inquests are on. Sometimes they do openings without telling us because they fail to update the website in the morning. The coroner's court in a year ago was a stand alone building, now it's in the town hall and you have to wait because there's security doors only go into reception. You can't gain access so easily."

\section{Commitment to public interest reporting}

Despite these difficulties, all the journalists reiterated their commitment to public interest reporting, and believed firmly in the importance of covering inquests.

Ms Simpson said: "There is a public interest in something that has happened, like a nasty crash where several people have been involved and people remember it, it should be out there what happened in a 
factual way. People will speculate on forums and local news sites. An inquest is the accurate, legal record of what actually happened.

"When I was a reporter, I went to a really upsetting inquest for a young man who jumped in front of a train. The train driver was called to give evidence. He was very shaken and the coroner excused him because he could hardly speak. Covering the inquest shows he wasn't at fault and there was nothing he could have done. The man had sadly chosen to take his own life. It is important with something like that for us to report it and put it out there so people know he didn't do anything wrong. This person deserves that to be known and we are informing the public of the legal, factual record of what happened."

Reporter Amy Farnworth said inquests could also raise broader issues that needed attention: "We have had a lot of coroners issue warnings to young men telling them to talk to someone and seek help because there has been an increase in male suicides."

Mr Martin felt the presence of reporters was important because of the lack of transparency in the inquest system. When writing features, he found it impossible to get local data on issues such as drugs deaths or suicides because there was no public record. Whereas magistrates courts routinely sent lists of outcomes, coroners' courts did not.

He said: "It's a major issue. It's one of those areas that are quite sensitive, you can't go in there all guns blazing. You can't go to war with them."

\section{Discussion}

It is clear that inquests in the UK are being under-reported. Although some inquests may have little public interest value, a rate of 11 per cent is worryingly low.

As with local democracy reporting, there are some "news deserts" in which inquests are reported only in exceptional circumstances. In Newcastle, there were no examples of a case that had been attended by a reporter for local media in the four-week period. In Bradford, Birmingham and Blackpool, only one was covered and that was either due to a national organisation being in attendance or because they were contacted by the family.

Increasingly, local news organisations are struggling for revenue which creates difficult decisions about how to allocate precious staffing resources. With little background information, it is difficult to justify covering lengthy inquests, which may turn out to have little public interest value.

But this means important cases may be effectively hidden from public view. Some of the inquests not covered included the death of a one-month old baby, a three-year-old and a number of people in their 20s. Missing these could have meant there was a lack of accountability. Although the coroner would have written to interested parties with his recommendations, without public knowledge there is less pressure for the recommendations to be heeded.

Lucy McKay, policy and communications officer at INQUEST, said open justice was an essential part of the inquest process, and was often compromised by a lack of openness in coroners' courts. 
She said: "Often the only way to find out what is being said in open court at inquests is to be there at the time. If Coroners do not write a Prevention of Future deaths report, there is no published public record of the inquest hearing or conclusions.

"This is where local media comes in, who in our experience are often the only journalists committed to spending time in the court, as well as keeping up with bereaved families over a long period, not just when there is breaking news. But more and more we find local journalists just cannot find the time or resources to allow them to undertake this important coverage, and as such important cases are missed."

It is clear from the interviews with journalists and editors that they are well aware of their responsibilities, but that they need better information in order to make decisions about coverage, as it is unlikely there will be a resurgence in revenue.

Firstly, information provided by coroners' offices is patchy despite official recommendations (Thornton, 2016). Whilst some provide comprehensive information, others provide only name and date of the inquest. This has an impact on coverage. Journalists need more data in order to be able to make informed decisions about resources.

Secondly, although journalists use the official listings provided, few will send a reporter to an inquest if they don't already have some prior background knowledge of the details surrounding the death.

Information about a death needs to be provided to reporters at a much earlier stage so that the case can be followed from beginning to end. At the moment, either due to lack of resources or changing agendas, police are failing to provide sufficient, timely information on some deaths.

This problem is exacerbated by a breakdown in relationships between reporters and police officers. Reporters have been increasingly encouraged to run enquiries through police press offices rather than the officers themselves. Editors interviewed here say this can cause delays in information being passed on.

In addition, police press offices appear to be acting more like private company public relations teams, with a remit to bolster the perception of the police rather than provide a public service of informing the public. This is a concerning trend. Further research is required to explore and understand the wider impact of this.

The gaps in knowledge could be filled by coroners' officers at opening stage, but editors' interviews suggest their availability is also patchy at best.

Although better relationships would clearly result in better communication, editor Wayne Ankers said this was not a perfect solution: "It should not just be about a specific reporter who had a specific relationship with a specific person. It should not be reliant on one person being in the office. It should be that there's some information that [they] are duty bound to give."

Despite a resurgence of interest in public interest local reporting, it is impossible to turn the clock back to the routine, friendly, cup-of-tea-and-a-chat relationships that once typified local journalism. Nor is it possible to increase news organisations' resources to pre-internet levels.

We would therefore recommend national guidelines on public availability of information on all deaths at which any emergency services attend. This need not create an increased burden of paperwork on police 
officers. It simply means all reports involving a death will automatically go to existing press officers who can release information.

In addition, we would recommend that coroners' officers be encouraged to respond fully to press inquiries regarding openings.

Inquests are amongst the most important of all public inquiries. In the absence of a criminal court case, they may be the only opportunity for the facts relating to a death to be set out. They are an antidote to rumour and hearsay. Inquests provide information about the problems of a society at granular level: suicides, drug problems and preventable accidents of all kinds. They should not disappear from sight.

\section{Declaration of Interest}

The authors have received no funding for this research, and have received no financial interest or benefit from it.

\section{Data Availability}

The data that support the findings of this study will be made openly available in https://clok.uclan.ac.uk/ by the end of August. DOls will then be provided.

\section{Bibliography}

Bagshaw, T. (2019). What happens when our local news disappears? How UK local newspapers are closing and coverage of court proceedings is not happening. Index on Censorship, 48(1), 29-31. doi:10.1177/0306422019842090

Barraclough, B. S. (1977). Do Newspaper Reports of Coroners' Inquests Incite People to Commit Suicide? British Journal of Psychiatry, 131(5), 528-532. doi:10.1192/bjp.131.5.528

Binns, A. (2001, November 23). Daughter died 'for the sake of a few pence'. Yorkshire Post. Retrieved from https://www.yorkshirepost.co.uk/news/latest-news/daughter-died-for-the-sake-of-a-fewpence-1-2419200

CBS. (2019, March 11). Losing local newspapers leaves many communities in the dark. Retrieved July 4, 2019, from CBS News: https://www.cbsnews.com/news/decline-of-newspapers-leaves-manycommunities-in-the-dark/

Fagan, J., Lyons, S., \& Smyth, B. P. (2014, July/August). Content Analysis of Newspaper Reports on Alcohol-Related Deaths, Alcohol and Alcoholism. 49(4), 479-483. doi:doi.org/10.1093/alcalc/agu015

Firmstone, J. (2016). Mapping Changes in Local News . Journalism Practice, 10(7), 928-938. doi:10.1080/17512786.2016.1165136 
Gans, H. (2010). News and the News Media in the Digital Age: Implications for Democracy. Daedalus, 139(2), 8-17.

Himmler, C. B. (2011). Newspaper Circulation and Local Government Efficiency. The Scandinavian Journal of Economics, 113(2). doi:10.1111/j.1467-9442.2010.01633.x

House of Commons. (2001, December 4). Labelling of Drugs EDM512. Retrieved from Parliament UK: https://edm.parliament.uk/early-day-motion/21306\#collapse-amendments

Kakar, A. (2018, March 27). Some 40 UK local newspapers closed in 2017 with net loss of 45 jobs, new research shows. Retrieved July 4, 2019, from Press Gazette: https://www.pressgazette.co.uk/some-40-uk-local-newspapers-closed-in-2017-with-net-loss-of45-jobs-new-research-shows/

Lucraft, H. H. (2018, June). Report of the Chief Coroner to the Lord Chancellor Fifth Annual Report: 20172018. Retrieved July 4, 2019, from gov.uk: https://assets.publishing.service.gov.uk/government/uploads/system/uploads/attachment_dat a/file/764720/report-of-the-chief-coroner-lord-chancellor-2017-18.pdf

Mclntosh, S. (2016). Taken lives matter: Open justice and recognition in inquests into deaths at the hands of the state. International Journal of Law in Context, 12(2), 141-161. doi:10.1017/S1744552316000057

Moore, G. R. (2016). Monopoloising Local News: Is there an emerging local democratic deficit in the UK due to the decline of local newspapers? London: Centre for the Study of Media, Communication and Power, King's College.

Nielsen, R. K. (2015). Local Journalism: The Decline of Newspapers and the Rise of Digital Media. Oxford: Reuters Institute for the Study of Journalism.

Rubado, M. E. (2019, April ). Political Consequences of the Endangered Local Watchdog: Newspaper Decline and Mayoral Elections in the United States. Urban Affairs Review. doi:10.1177/1078087419838058.

Smith, J. (2003, July). gov.uk. Retrieved July 4, 2019, from www.gov.uk: https://assets.publishing.service.gov.uk/government/uploads/system/uploads/attachment_dat a/file/273227/5854.pdf

Sommerlad, J. (2018, April 26). Harold Shipman: Who was 'Doctor Death', how many of his patients did he kill and how was he finally caught? The Independent. Retrieved July 4, 2019, from https://www.independent.co.uk/news/uk/crime/harold-shipman-doctor-death-serial-killer-gpmass-murderer-hyde-manchester-itv-documentary-a8323176.html

Stromberg, J. M. (2010, April). Press Coverage and Political Accountability. Journal of Political Economy, 118(2), 355-408. doi:10.1086/652903

Tait, G., \& Carpenter, B. J. (2013). Suicide and the therapeutic coroner : inquests, governance and the grieving family. International Journal for Crime, Justice and Social Democracy, 2(3), 92-104. 
Thornton, H. J. (2016, September 30). Guidance No. 25 Coroners and the Media. Retrieved July 4, 2019, from www.judiciary.uk: https://www.judiciary.uk/wp-content/uploads/2016/10/guidance-no25-coroners-and-the-media.pdf

Thornton, H. J. (2016, June). Report of the Chief Coroner to the Lord ChancellorThird Annual Report: 2015-2016. Retrieved July 4, 2019, from Courts and Tribunals Judiciary: https://www.judiciary.uk/wp-content/uploads/2016/09/chief_coroner_report_2016_web2.pdf

Waterson, J. (2019, May 7). Read all about it? How local papers' decline is starving communities of news. Retrieved July 4, 2019, from The Guardian: https://www.theguardian.com/uknews/2019/may/07/read-all-about-it-how-local-papers-decline-is-starving-communities-ofnews

Woodruff, J. (2019, January 31). How the decline of newspapers creates 'news deserts' around the country. Retrieved July 4, 2019, from PBS: https://www.pbs.org/newshour/show/how-thedecline-of-local-newspapers-exacerbates-polarization

Yazaki, Y. (2017, September). Newspapers and political accountability: evidence from Japan. Public Choice, 172(3-4), 311-331. doi:10.1007/s11127-017-0444-x

Yorkshire Post. (2003, May 8). Trusts launch trial to slash drug errors. Yorkshire Post. Retrieved from https://www.yorkshirepost.co.uk/news/latest-news/trusts-launch-trial-to-slash-drug-errors-12517137

Ziesenis, E. B. (1991). Suicide Coverage in Newspapers: An Ethical Consideration. Journal of Mass Media Ethics, 6(4), 234-244. doi:10.1207/s15327728jmme0604_4 